\title{
Development of a novel method for the quantification of tyrosine 39 phosphorylated $\alpha$ - and $\beta$-synuclein in human cerebrospinal fluid
}

\author{
Chan Hyun Na ${ }^{1,2,3^{*}}$, Gajanan Sathe ${ }^{3,9}$, Liana S. Rosenthal ${ }^{2}$, Abhay R. Moghekar ${ }^{2}$, Valina L. Dawson 1,2,3,5, \\ Ted M. Dawson ${ }^{1,2,3,6,7^{*}}$ and Akhilesh Pandey $3,4,8,10^{*}$
}

\begin{abstract}
Background: Parkinson's disease (PD) is the second most prevalent neurodegenerative disorder. Biomarkers that can help monitor the progression of PD or response to disease-modifying agents will be invaluable in making appropriate therapeutic decisions. Further, biomarkers that could be used to distinguish PD from other related disorders with PDlike symptoms will be useful for accurate diagnosis and treatment. C-Abl tyrosine kinase is activated in PD resulting in increased phosphorylation of the tyrosine residue at position 39 (Y39) of a-synuclein (a-syn) (pY39 a-syn), which contributes to the death of dopaminergic neurons. Because pY39 a-syn may be pathogenic, monitoring pY39 a-syn could allow us to diagnose presymptomatic PD and help monitor disease progression and response to treatment. We sought to investigate if increased phosphorylation of pY39 a-syn can be detected in the cerebrospinal fluid (CSF) of PD patients by targeted mass spectrometry.
\end{abstract}

Methods: Here, we report a two-step enrichment method in which phosphotyrosine peptides were first enriched with an anti-phosphotyrosine antibody followed by a second round of enrichment by titanium dioxide $\left(\mathrm{TiO}_{2}\right)$ beads to detect EGVLPYVGSK sequence derived from tyrosine 39 region of $a$ - and $\beta$-synuclein (a $\beta$-syn). Accurate quantification was achieved by adding a synthetic heavy version of pY39 a $\beta$-syn peptide before enzymatic digestion.

Results: Using the developed enrichment methods and optimized parallel reaction monitoring (PRM) assays, we detected pY39 a -syn peptide in human CSF and demonstrated that the ratio of pY39 aß-syn to Y39 aß-syn was significantly increased in the CSF of patients with PD.

Conclusions: We anticipate that this optimized two-step enrichment-based PRM detection method will help monitor c-Abl activation in PD patients and can also be used to quantify other phosphotyrosine peptides of low abundance in biological samples.

Keywords: Parkinson's disease, a-Synuclein, $\beta$-Synuclein, Phosphotyrosine, Cerebrospinal fluid, Parallel reaction monitoring

*Correspondence: chanhyun@jhmi.edu; tdawson@jhmil.edu; pandey. akhilesh@mayo.edus

${ }^{1}$ Neurodegeneration Program, Institute for Cell Engineering, Johns Hopkins University School of Medicine, Baltimore, MD 21205, USA

${ }^{10}$ Present Address: Laboratory Medicine and Pathology, Mayo Clinic, Rochester, MN 55902, USA

Full list of author information is available at the end of the article

\section{Introduction}

Although the exact pathogenic mechanism of PD has yet to be established, $\alpha$-syn is an important mediator, and moreover, the phosphorylation of $\alpha$-syn may contribute to the pathogenesis via increased aggregation and toxicity $[1,2]$. Recently, pY39 $\alpha$-syn has been shown to be

(c) The Author(s) 2020. This article is licensed under a Creative Commons Attribution 4.0 International License, which permits use, sharing, adaptation, distribution and reproduction in any medium or format, as long as you give appropriate credit to the original author(s) and the source, provide a link to the Creative Commons licence, and indicate if changes were made. The images or other third party material in this article are included in the article's Creative Commons licence, unless indicated otherwise in a credit line to the material. If material is not included in the article's Creative Commons licence and your intended use is not permitted by statutory regulation or exceeds the permitted use, you will need to obtain permission directly from the copyright holder. To view a copy of this licence, visit http://creativeco mmons.org/licenses/by/4.0/. The Creative Commons Public Domain Dedication waiver (http://creativecommons.org/publicdomain/ zero/1.0/) applies to the data made available in this article, unless otherwise stated in a credit line to the data. 
closely correlated to disease severity and progression [1, $3,4]$. Thus, pY39 $\alpha$-syn levels in the brain could potentially serve as a marker for presymptomatic diagnosis, disease progression, and therapeutic response. Since pY39 $\alpha$-syn is increased in the brain of PD patients, we postulated that this increased phosphorylation could be reflected in the CSF [5].

For targeted detection and quantitation of known proteins or post-translational modifications (PTMs) on those proteins, PRM mass spectrometry (PRM-MS) has been widely used $[6,7]$. To quantify pY39 $\alpha$-syn using PRM-MS, pY39 $\alpha \beta$-syn peptide, EGVLPYVGSK will be monitored. Although pY39 $\alpha \beta$-syn peptide is shared between $\alpha$-syn and $\beta$-syn, we reasoned that the peptide can still serve as a PD biomarker unless the phosphorylation level of $\beta$-syn changes to the opposite direction to that of $\alpha$-syn in PD. When the abundance of a target protein is too low, the target protein or the derived peptide sometimes can be detected using various enrichment methods such as immunoprecipitation or affinity purification of target proteins or peptides [810]. Here, we report a method specifically developed to detect pY39 $\alpha \beta$-syn peptide in human CSF combining an enrichment method with the PRM-MS approach. Because the abundance of pY39 $\alpha \beta$-syn in CSF is too low to be detected even with a conventional enrichment method, we developed a two-step enrichment approach using an anti-phosphotyrosine antibody and $\mathrm{TiO}_{2}$ beads followed by PRM-MS analysis for detection and quantitation of pY39 $\alpha \beta$-syn peptide. This method allowed us to establish that the ratio of pY39 $\alpha \beta$-syn to Y39 $\alpha \beta$-syn peptides in the CSF can serve as a potential biomarker for the diagnosis and prognosis of PD. Furthermore, this method is applicable to the extremely sensitive detection of other phosphotyrosine peptides as well.

\section{Methods}

\section{Collection of CSF samples}

The CSF specimens were collected from normal pressure hydrocephalus (NPH) patients, PD patients or cognitively normal healthy control individuals evaluated by investigators at the Johns Hopkins Hospital. The CSF samples from NPH patients were used for method optimization. The CSF samples from PD or control individuals were used to compare pY3 $\alpha \beta$-syn peptide levels between the two groups. The individuals who are cognitively normal or show PD symptoms were diagnosed after extensive clinical and cognitive testing. All PD patients met the UK Brain Bank criteria for PD diagnosis [11]. After the collection of CSF samples by lumbar puncture, the samples were centrifuged for $10 \mathrm{~min}$ at $1500 \times g$, aliquoted, and stored at $-80{ }^{\circ} \mathrm{C}$ within $1 \mathrm{~h}$ of acquisition. The demographic and clinical characteristics of the PD patients and control individuals are shown in Additional file 1: Table S1.

\section{Enrichment of pY39 a $\beta$-syn peptide only with anti-phosphotyrosine antibody}

Approximately $5.5 \mathrm{mg}$ of proteins derived from $9 \mathrm{ml}$ of CSF were lysed in $4 \mathrm{M}$ urea and $50 \mathrm{mM}$ triethylammonium bicarbonate (TEAB) followed by a reduction with $10 \mathrm{mM}$ dithiothreitol for $1 \mathrm{~h}$ at room temperature (RT) and alkylation with $30 \mathrm{mM}$ iodoacetamide for $30 \mathrm{~min}$ at $\mathrm{RT}$ in the dark. The proteins were then digested with an endoproteinase Lys-C (1:100; Wako Chemicals, Richmond, VA) by incubating at RT for 3 h. Subsequently, trypsin digestion was conducted by diluting the urea concentration to $2 \mathrm{M}$ by adding 1 volume of $50 \mathrm{mM}$ TEAB followed by adding sequencing-grade trypsin (1:50; Promega, Madison, WI) and incubating at $37{ }^{\circ} \mathrm{C}$ overnight. The peptide samples were desalted with $\mathrm{C}_{18}$ Sep-Pak (Waters Corporation, Milford, MA) and freeze-dried. The pY39 $\alpha \beta$-syn endogenous peptide (EGVLPYVGSK) was enriched by performing phosphotyrosine peptide enrichment with PTMScan pY1000 antibody according to the manufacturer's instruction (Cell Signaling Technology, Danvers, MA). Briefly, the $\sim 2.75 \mathrm{mg}$ of CSF peptides derived from $9 \mathrm{ml}$ of CSF was reconstituted in $1.4 \mathrm{ml}$ of immunoaffinity purification buffer (IAP, $50 \mathrm{mM}$ MOPS, $\mathrm{pH}$ 7.2, $10 \mathrm{mM} \mathrm{Na}_{2} \mathrm{HPO}_{4}$ and $50 \mathrm{mM} \mathrm{NaCl}$ ). The peptide solution was cleared by centrifugation for $5 \mathrm{~min}$ at $10,000 \times g$ at $4{ }^{\circ} \mathrm{C}$, and the supernatant was subject to the phosphotyrosine enrichment. After washing $40 \mu \mathrm{l}$ of phosphotyrosine agarose beads three times with PBS, the CSF peptide solution was added to the washed beads followed by incubation at $4^{\circ} \mathrm{C}$ for $2 \mathrm{~h}$ with rotation. Subsequently, the supernatant was removed, and the beads were washed thrice with $1 \mathrm{ml}$ of IAP buffer and twice with $1 \mathrm{ml}$ of ice-cold water. The bound phosphotyrosine peptides were eluted by adding $55 \mu \mathrm{l}$ of $0.15 \%$ trifluoroacetic acid (TFA) and incubated at RT for $10 \mathrm{~min}$. After incubation, the tube was centrifuged at $2000 \times g$ for $1 \mathrm{~min}$ and the solution was transferred to a new tube. This elution was repeated once again with $50 \mu \mathrm{l} 0.15 \%$ TFA. Twenty fmol of synthetic heavy $\left({ }^{13} \mathrm{C}_{6}\right.$, ${ }^{15} \mathrm{~N}_{2}$-lysine) pY39 $\alpha \beta$-syn peptide was added followed by desalting with $\mathrm{C}_{18}$ StageTip. The eluted peptides were then dried using a SpeedVac followed by reconstitution in $15 \mu \mathrm{l}$ of $0.1 \%$ formic acid prior to mass spectrometry analysis. 


\section{Enrichment of pY39 a $\beta$-syn peptide}

both with anti-phosphotyrosine antibody and $\mathrm{TiO}_{2}$ beads

For quantification of pY39 $\alpha \beta$-syn peptides from $1 \mathrm{ml}$ ( $\sim 0.6 \mathrm{mg}$ of proteins) of CSF samples from PD patients or control samples with both PTMScan pY1000 antibody and TiO2, 20 fmol of synthetic heavy pY39 $\alpha \beta$-syn peptide was added to CSF. CSF proteins were lysed in $4 \mathrm{M}$ urea and $50 \mathrm{mM}$ TEAB followed by a reduction with $10 \mathrm{mM}$ dithiothreitol for $1 \mathrm{~h}$ at RT and alkylation with $30 \mathrm{mM}$ iodoacetamide for $30 \mathrm{~min}$ at RT in the dark. The proteins were then digested with an endoproteinase Lys-C (1:100; Wako Chemicals, Richmond, VA) by incubating at RT for $3 \mathrm{~h}$. Sequentially trypsin digestion was conducted by diluting the urea concentration to $2 \mathrm{M}$ by adding 1 volume of $50 \mathrm{mM}$ TEAB followed by adding sequencing-grade trypsin (1:50; Promega, Madison, WI) and incubating at $37^{\circ} \mathrm{C}$ overnight. The peptide samples were desalted with $\mathrm{C}_{18}$ Sep-Pak (Waters Corporation, Milford, MA) and freeze-dried. The synthetic heavy and endogenous pY39 $\alpha \beta$-syn peptides were enriched by performing phosphotyrosine peptide enrichment with PTMScan pY1000 antibody according to the manufacturer's instruction with minor modifications (Cell Signaling Technology, Danvers, MA). Briefly, the $\sim 0.3 \mathrm{mg}$ of CSF peptides derived from $1 \mathrm{ml}$ of CSF was reconstituted in $200 \mu \mathrm{l}$ of IAP buffer. The peptide solution was cleared by centrifugation for $5 \mathrm{~min}$ at $10,000 \times g$ at $4{ }^{\circ} \mathrm{C}$ and the supernatant was subjected to the phosphotyrosine enrichment. After washing $20 \mu$ of phosphotyrosine agarose beads three times with PBS, the CSF peptide solution was added to the washed beads followed by incubation at $4{ }^{\circ} \mathrm{C}$ for $2 \mathrm{~h}$ with rotation. Subsequently, the supernatant was removed and the beads were washed once with ice-cold water. The bound phosphotyrosine peptides were eluted by adding $55 \mu \mathrm{l}$ of $0.15 \%$ TFA and incubated at RT for $10 \mathrm{~min}$. After incubation, the tube was centrifuged at $2000 \times g$ for $1 \mathrm{~min}$ and the solution was transferred to a new tube. This elution was repeated once again with $50 \mu \mathrm{l} 0.15 \%$ TFA. The eluate was dried using a SpeedVac and the phosphorylated peptides were enriched again using $\mathrm{TiO}_{2}$ beads as described previously [12]. Briefly, $0.6 \mathrm{mg}$ of $\mathrm{TiO}_{2}$ beads (Titansphere) resuspended in $40 \mu \mathrm{l}$ of binding buffer (65\% acetonitrile (ACN) and $2 \%$ TFA) were added to the peptides followed by incubation at RT for $20 \mathrm{~min}$ with shaking at $1400 \mathrm{rpm}$. The peptides were transferred to a $\mathrm{C}_{8}$ StageTip and centrifuged at $2000 \times g$ for $2 \mathrm{~min}$. Two hundred $\mu \mathrm{l}$ of the washing buffer (65\% ACN and $0.1 \%$ TFA) was added and centrifuged at $2000 \times g$ for $5 \mathrm{~min}$. This washing was repeated once again. The phosphopeptides were eluted by adding $40 \mu \mathrm{l}$ of elution buffer $\left(1 \% \mathrm{NH}_{4} \mathrm{OH}\right.$ and $\left.40 \% \mathrm{ACN}\right)$ and centrifuging at $200 \times g$ for $2 \mathrm{~min}$. The eluted peptides were then dried using a SpeedVac followed by reconstitution in $15 \mu \mathrm{l}$ of $0.1 \%$ formic acid prior to mass spectrometry analysis.

\section{Calculation of the limits of detection and quantification}

The limits of detection (LOD) were calculated as: $\mathrm{LOD}=\mu_{\mathrm{B}}+\mathrm{t}_{(1-\beta)}\left(\sigma_{\mathrm{B}}+\sigma_{\mathrm{S}}\right) / \sqrt{ } \mathrm{n}$, where $\mu_{\mathrm{B}}$ is the estimated mean of blank samples, $t_{(1-\beta)}$ is 95 percentile of the standard $t$ distribution on $f$ degrees of freedom, $\sigma_{B}$ is the standard deviation of the blank samples, $\sigma_{\mathrm{S}}$ is the standard deviation of the low concentration samples, and $\mathrm{n}$ is the number of replicates. The limits of quantification (LOQ) were estimated as 3x LOD [13].

\section{Detection of Y39 a $\beta$-syn peptide}

To normalize the amount of pY39 $\alpha \beta$-syn peptide in each sample based on the Y39 $\alpha \beta$-syn peptide present in each sample, the amount of $Y 39 \alpha \beta$-syn peptide in each sample was also measured. Twenty fmol of heavy $\left({ }^{13} \mathrm{C}_{6}\right.$, ${ }^{15} \mathrm{~N}_{2}$-lysine) Y39 $\alpha \beta$-syn peptide (EGVLYVGSK ${ }^{*}$ ) for the quantification of the endogenous Y39 $\alpha \beta$-syn peptide were added to $5 \mu \mathrm{g}$ of CSF peptides followed by desalting with $\mathrm{C}_{18}$ StageTip and LC-MS/MS analysis.

\section{LC-MS/MS analysis}

The prepared peptides were analyzed on an Orbitrap Fusion Lumos Tribrid Mass Spectrometer coupled to an EASY-nLC 1200 nano-flow liquid chromatography system (Thermo Fisher Scientific). The peptides from each fraction were reconstituted in $15 \mu \mathrm{l}$ of $0.1 \%$ formic acid and loaded onto an Acclaim PepMap100 Nano-Trap Column $(100 \mu \mathrm{m} \times 2 \mathrm{~cm}$, Thermo Fisher Scientific) packed with $5 \mu \mathrm{m} \mathrm{C}_{18}$ particles at a flow rate of $5 \mu \mathrm{l}$ per min. The flow rate employed was $250 \mathrm{nl} / \mathrm{min}$ using a linear gradient of $10 \%$ to $35 \%$ solvent B $(0.1 \%$ formic acid in $95 \%$ acetonitrile) over 45 minutes on an EASY-Spray column (50 $\mathrm{cm} \times 75 \mu \mathrm{m}$ ID, Thermo Fisher Scientific) packed $2 \mu \mathrm{m} \mathrm{C}_{18}$ particles (Thermo Fisher Scientific), which was fitted with an EASY-Spray ion source operated at a voltage of $2.7 \mathrm{kV}$. Mass spectrometry analysis was completed in a data-dependent manner with a full scan in the mass-to-charge ratio $(\mathrm{m} / z)$ range of 350 to 1550 followed by targeted MS2. MS1 was measured at a resolution of 120,000 (at $m / z$ of 200). MS2 scan was acquired by fragmenting precursor ions using the higher-energy collisional dissociation (HCD) method and detected at a mass resolution of 30,000 (at $\mathrm{m} / \mathrm{z}$ of 200). Automatic gain control was set to 500,000 and 100,000 ions for MS1 and MS2, respectively. The maximum ion injection time for MS1 was set to 100 ms. Maximum ion times for MS2 
were set to 2500 and $500 \mathrm{~ms}$ for pY39 and Y39 $\alpha \beta$-syn peptides, respectively. HCD normalized collisional energy (NCE) was set to 25 , if not specified. The precursor isolation window was set to $1.6 \mathrm{~m} / z$. Internal calibration was carried out using the lock mass option $(\mathrm{m} / \mathrm{z}$ 445.1200025) from ambient air. For the light and heavy pY39 $\alpha \beta$-syn peptides, $m / z 516.244$ and $m / z 520.251$ were monitored, respectively. For the light and the heavy Y39 $\alpha \beta$-syn peptides, $m / z 476.261$ and $m / z 480.268$ were monitored, respectively.

\section{Data analysis}

The quantification of relative peptide abundance was performed using Skyline software [14]. The levels of pY39 $\alpha \beta$-syn were normalized by Y39 $\alpha \beta$-syn peptide.

\section{Results}

To detect pY39 $\alpha \beta$-syn peptide in CSF samples, we initially tried to detect it directly from the digests of CSF samples using PRM but were not able to detect it. Subsequently, we tried an enrichment of $\alpha$-syn protein using an anti- $\alpha$-syn antibody or enrichment of

\section{a}

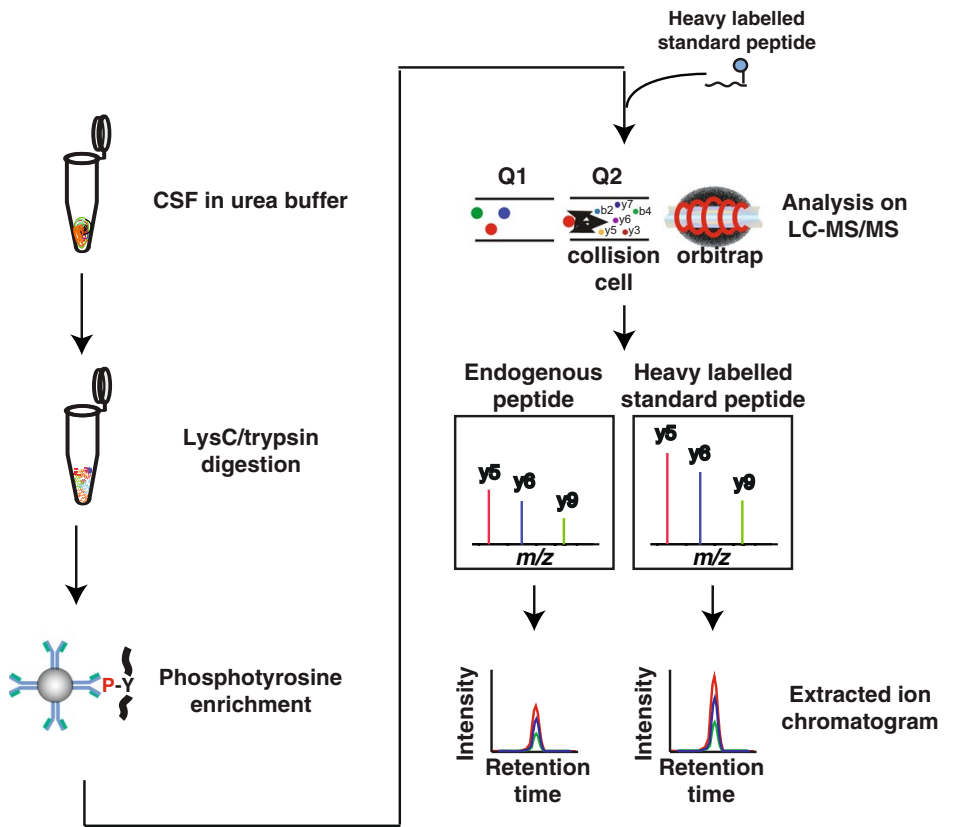

b

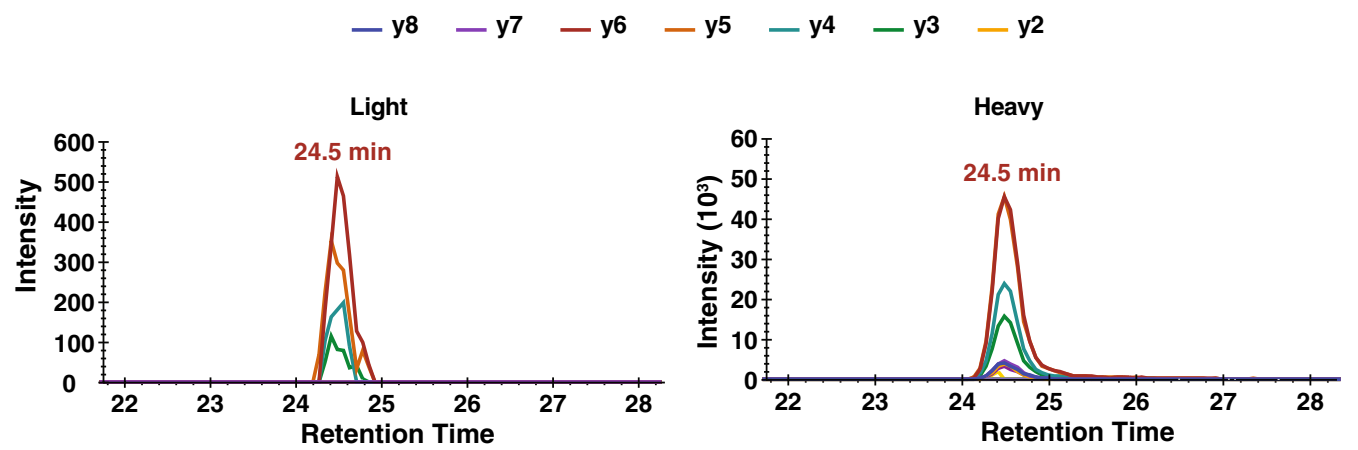

Fig. 1 The schematic diagram for the research strategy and the detection of endogenous pY39 aß-syn peptides. a The experimental strategy for pY39 aß-syn peptide enrichment using an anti-phosphotyrosine antibody. CSF proteins were digested with Lys-C and trypsin followed by phosphotyrosine peptide enrichment. To validate the detection of the endogenous pY39 aß-syn peptide, a heavy pY39 aß-syn standard peptide was added before PRM analysis. The endogenous light and heavy standard pY39 aß-syn peptides were monitored under PRM mode followed by a quantification using Skyline software. $\mathbf{b}$ The extracted chromatogram of $y$ ion series from either endogenous or heavy standard pY39 a peptide 
phosphopeptides using $\mathrm{TiO}_{2}$ or Immobilized metal affinity chromatography (IMAC). However, none of these enrichment methods were successful in detecting pY39 $\alpha \beta$-syn peptide. We reasoned that because pY39 $\alpha \beta$-syn peptide is a tyrosine-phosphorylated peptide, we could further reduce peptide complexity by performing phosphotyrosine peptide enrichment to remove phosphoserine and phosphothreonine peptides, which constitute the majority of phosphopeptides. Using this procedure, we were able to detect the endogenous pY39 $\alpha \beta$-syn peptide from $9 \mathrm{ml}$ of CSF (Fig. 1a, b). Because $9 \mathrm{ml}$ of CSF is not practical volume in most cases for biomarker detection, we further optimized our methods to reduce the CSF volume required for the analysis.

\section{Optimizing the detection of pY39 a $\beta$-syn peptide}

To improve our detection sensitivity, we systematically evaluated the effect of HCD NCE energy, ion transfer capillary temperature and ESI spray voltage on detection.
For the HCD NCE evaluation, the HCD NCE value was increased from 24 to 32 . The pY39 $\alpha \beta$-syn peptide showed the highest intensity at 25 of HCD NCE (Fig. 2a). Next, we evaluated the temperature of the ion transfer capillary increasing it from 160 to $400{ }^{\circ} \mathrm{C}$ and pY39 $\alpha \beta$-syn peptide showed the highest intensity at $180{ }^{\circ} \mathrm{C}$ (Fig. 2b). We then evaluated ESI voltage optimization by increasing from 1500 to 3000. pY39 $\alpha \beta$-syn peptide showed the highest intensity at $3000 \mathrm{~V}$ (Fig. 2c). Interestingly, the intensity at $3000 \mathrm{~V}$ was $>3.5$-fold compared to the one observed at $1500 \mathrm{~V}$. Although the HCD NCE and the ion transfer capillary temperature did not change the intensity of pY39 $\alpha \beta$-syn peptide significantly, the ESI voltage seemed to be critical in increasing the sensitivity. We applied the optimized parameters for the detection of pY39 $\alpha \beta$-syn peptide except that we opted to use $2700 \mathrm{~V}$ instead of $3000 \mathrm{~V}$ for preserving column stability. A calibration curve with these optimized parameters permitted us to detect the target peptide at sub-attomole levels. The LOD and LOQ were 0.44 and 1.32 attomoles,
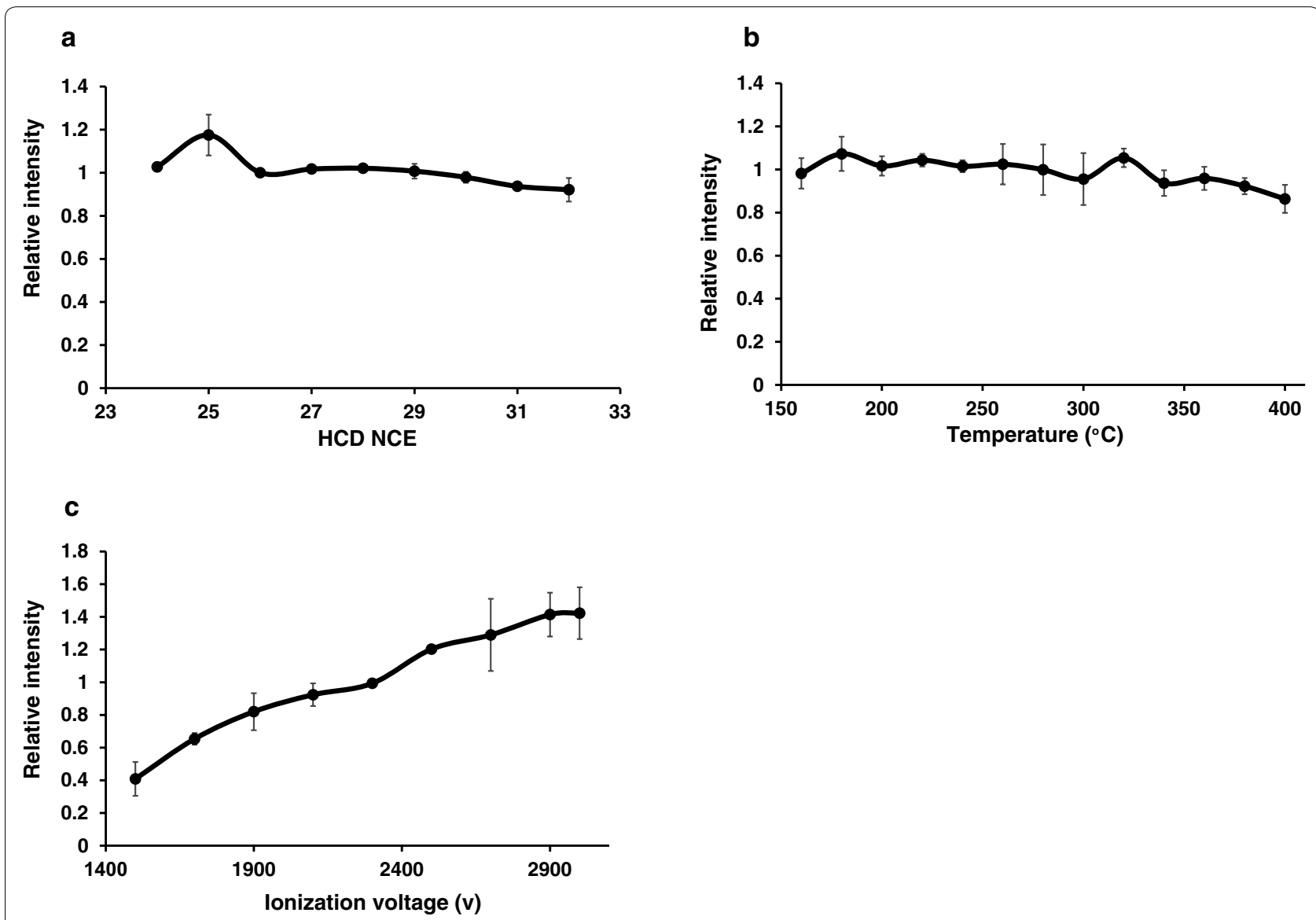

Fig. 2 Optimization of mass spectrometry parameters for pY39 peptide detection. a The relative intensity of the standard pY39 a $\beta$-syn peptide with different HCD NCEs. b The relative intensity of the standard pY39 aß-syn peptide with different ion transfer tube capillary temperatures. $\mathbf{c}$ The relative intensity of the standard pY39 a $\beta$-syn peptide with different ESI voltages 
respectively. The coefficient of variations (CV) was calculated as $26.19 \%$ at 1 attomole, $4.45 \%$ at 10 attomoles, $4.84 \%$ at 100 attomoles, $10.03 \%$ at 1 femtomole, $4.45 \%$ at 10 femtomoles and $8.93 \%$ at 100 femtomoles. The average $\mathrm{CV}$ of the 6 concentrations was 9.81\% (Additional file 2: Figure S1).

\section{Development of an enrichment method for pY39 a $\beta$-syn peptides}

To detect the pY39 $\alpha \beta$-syn peptide from an even smaller volume of CSF, we optimized the enrichment method as well. Even after the enrichment of phosphotyrosine peptides, $80-90 \%$ of peptides were still non-phosphorylated ones interfering with the detection of target peptides. Thus, the second step of $\mathrm{TiO}_{2}$-based phosphopeptide enrichment should further remove the non-phosphorylated peptides, and thereby, we expected that it would increase the sensitivity of detecting target peptides (Fig. 3a). Thus, we developed a two-step enrichment method by combining the antibody-based phosphotyrosine peptide enrichment method with the $\mathrm{TiO}_{2}$-based phosphopeptide enrichment method. To optimize this two-step detection method, we first evaluated the ratio of phosphotyrosine antibody-conjugated agarose beads to the input peptide amount. One femtomole of heavy pY39 $\alpha \beta$-syn peptide was incubated with various volumes of antibody-conjugated beads ranging from $2.5 \mathrm{ul}$ to $80 \mathrm{ul}$. The relative intensity of the heavy pY39 $\alpha \beta$-syn peptide showed saturation at $20 \mu \mathrm{l}$ of the agarose beads (Fig. 3b). We next optimized the ratio of $\mathrm{TiO}_{2}$ beads to input peptide amount. For this, 2 femtomoles of heavy pY39 $\alpha \beta$-syn peptide was incubated with various amounts of $\mathrm{TiO}_{2}$ beads ranging from $0.1 \mathrm{mg}$ to $3.2 \mathrm{mg}$. The pY39 $\alpha \beta$-syn peptide showed the highest intensity at $0.8 \mathrm{mg}$ of $\mathrm{TiO}_{2}$ beads (Fig. 3c).

\section{Measurement of $\mathrm{pY} 39$ a $\beta$-syn peptide in CSF samples from $\mathrm{PD}$ and control individuals}

Since the goal of this study was to quantify the endogenous pY39 $\alpha \beta$-syn peptide in CSF samples from PD patients and control individuals, we applied the optimized mass spectrometry parameters and sample preparation procedure to detect the pY39 $\alpha \beta$-syn peptides from $4 \mathrm{PD}$ and 4 control individuals as shown in Fig. 4a. To minimize any experimental bias and maximize the accuracy of quantification, synthetic heavy pY39 $\alpha \beta$-syn peptide was added to all CSF samples at the beginning of the sample preparation step [15]. When pY39 $\alpha \beta$-syn peptide levels in $1 \mathrm{ml}$ of CSF samples from PD patients were compared to the ones from controls, there was no statistically significant difference (Fig. 4b and Additional files 3: Table S2, 4). Because it is already known that total $\alpha$-syn levels are decreased in PD patients, we postulated that the levels of pY39 $\alpha \beta$-syn peptide normalized to the ones of Y39 $\alpha \beta$-syn peptide might help distinguish PD patients from controls. For this, we first measured the Y39 $\alpha \beta$-syn levels by spiking synthetic heavy Y39 $\alpha \beta$-syn peptide (Additional file 5: Figure S2). As we expected, Y39 $\alpha \beta$-syn peptide in CSF from PD patients showed a decreased abundance (Fig. 4c). Most importantly, the ratio of pY39 $\alpha \beta$-syn to $Y 39 \alpha \beta$-syn peptides in CSF from PD patients showed a noticeable increase ( 2.5 fold) with statistical significance $\left(P\right.$ value $\left.=8.4 \times 10^{-5}\right)$ (Fig. $4 d$ ). These results are potentially promising and will have to be validated in a larger cohort.

\section{Discussion}

In this study, we developed a two-step enrichment method to detect endogenous pY39 $\alpha \beta$-syn peptide in a sensitive manner from CSF samples using PRM-MS. This approach enabled us to detect the phosphorylated target peptide present at attomole levels per $\mathrm{ml}$ of CSF. The enrichment efficiency of phosphotyrosine peptides using the anti-phosphotyrosine antibody-conjugated beads in the first enrichment was usually $<15 \%$ owing to non-specifically bound peptides even after 5 washes. These non-specifically bound peptides increase the noise in PRM-MS experiments thereby reducing the detection sensitivity. These non-specifically bound peptides can be removed by more extensive washing but it will result in the loss of the target peptide at the same time. For this reason, we chose to remove the non-specifically bound peptides by the second enrichment step using $\mathrm{TiO}_{2}$ beads instead of washing the beads stringently losing the target peptide. Using this strategy, we were able to improve the detection sensitivity of the target peptide to the level of attomole per ml. While the endogenous pY39 $\alpha \beta$-syn peptide levels alone did not show a statistically significant difference between PD and control CSFs, the relative abundance of pY39 over Y39 $\alpha \beta$-syn peptides was strikingly different between the two groups with statistical significance. Our results suggest that the stoichiometry of tyrosine phosphorylation on the residue 39 of $\alpha \beta$-syn might be increased in patients with PD, although how much phosphorylation was derived from $\alpha$-syn still remains to be elucidated. The development of this method now makes it possible to test the utility of the pY39 over Y39 $\alpha \beta$-syn peptide ratio as a potential readout for c-Abl activity as well. In addition, this method is broadly applicable to the detection of other phosphotyrosine peptides in biological samples with minor modifications. 
a

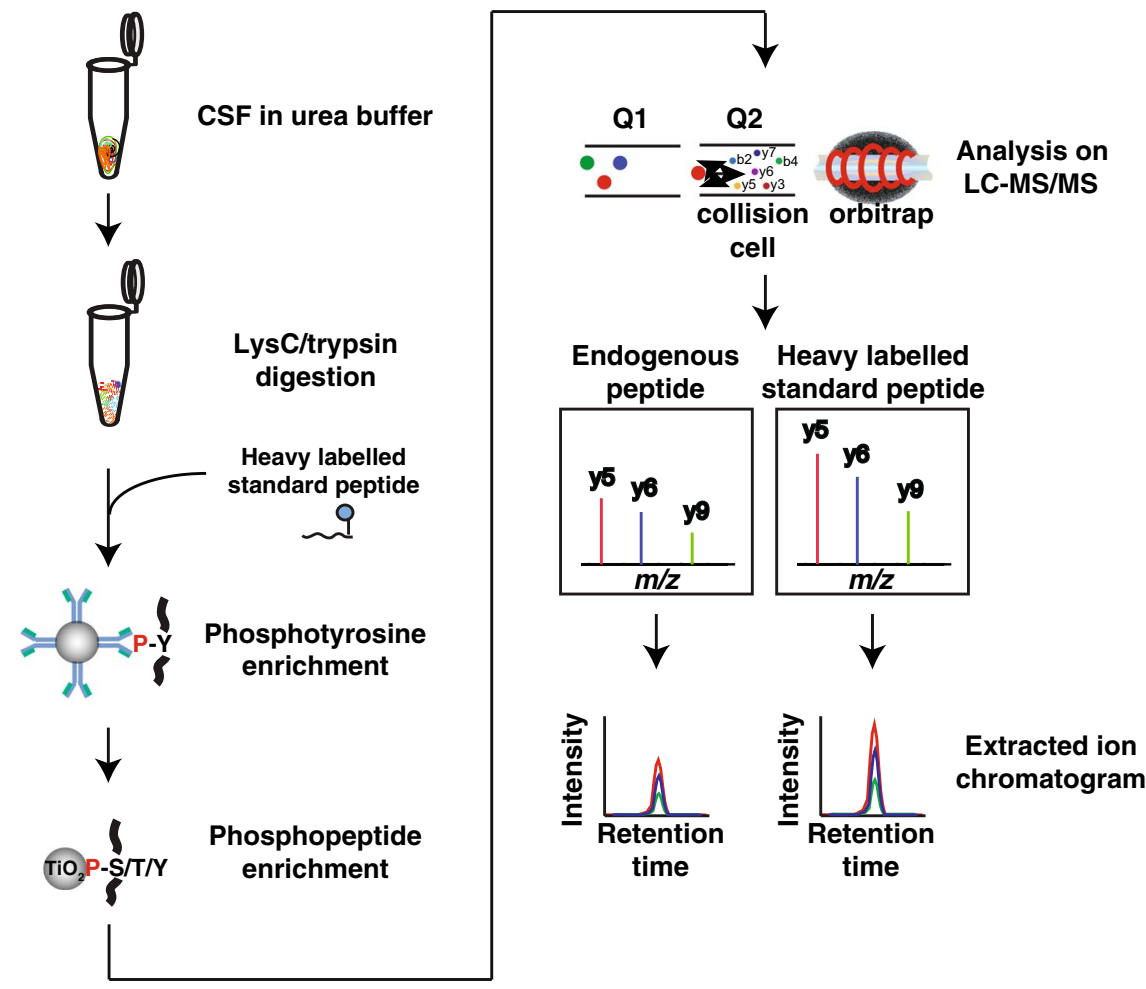

b

C
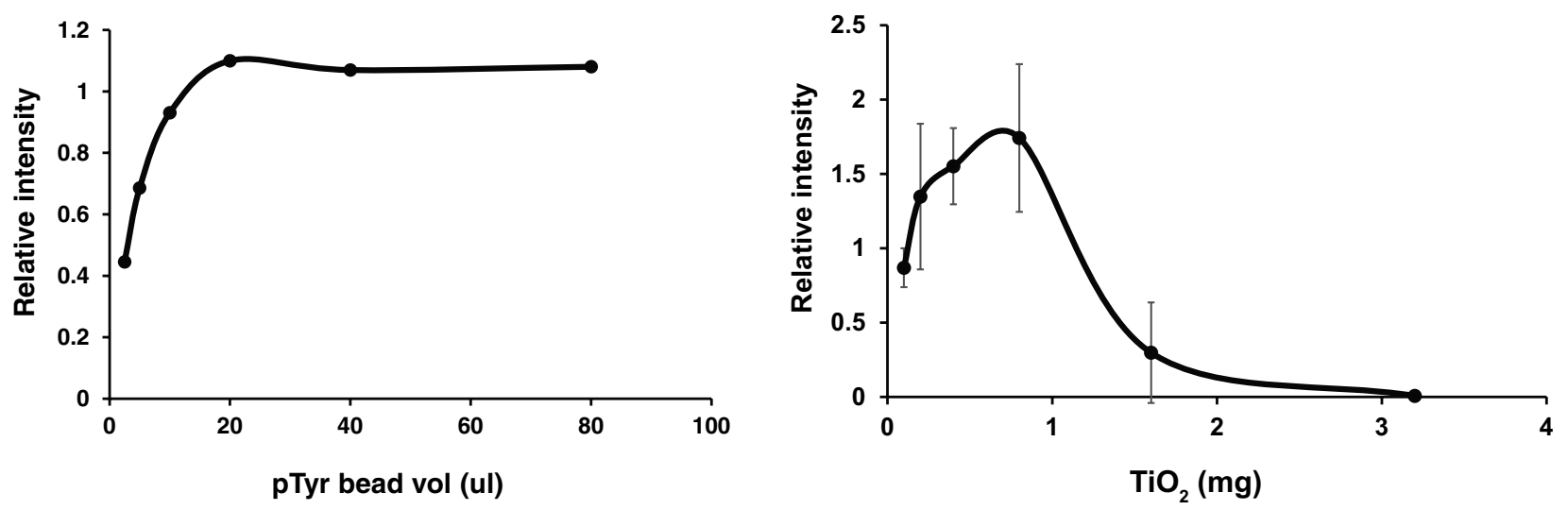

Fig. 3 Two-step enrichment strategy and the optimization of the two-step enrichment experiment conditions. a The experimental strategy for pY39 aß-syn peptide enrichment using the two-step enrichment approach in which phosphotyrosine peptides were enriched followed by total phosphopeptides were enriched using $\mathrm{TiO}_{2}$ beads. CSF proteins were digested with $\mathrm{Lys}-\mathrm{C}$ and trypsin. To monitor the enrichment efficiency, heavy standard pY39 aß-syn peptide was added before the two-step enrichment and the enrichments were conducted. The endogenous light and heavy standard pY39 aSyn were monitored under PRM mode followed by quantification using Skyline software. b Different volumes of agarose beads coupled with anti-phosphotyrosine antibodies were incubated with the target peptides to investigate the best ratio of anti-phosphotyrosine agarose beads to the target peptides. $\mathbf{c}$ Different amounts of $\mathrm{TiO}_{2}$ beads were incubated with the target peptides to investigate the best ratio of $\mathrm{TiO}_{2}$ beads to the target peptides 
a

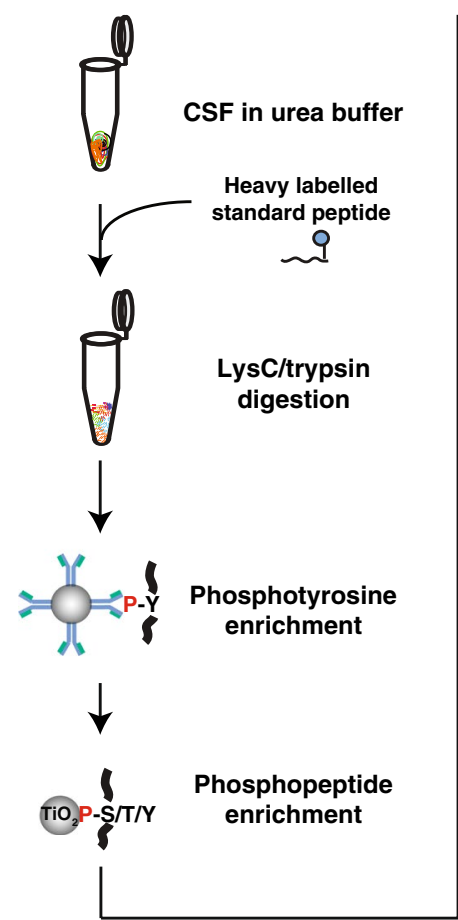

b

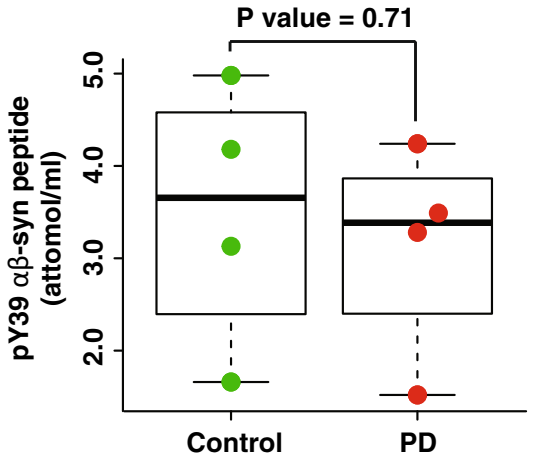

d

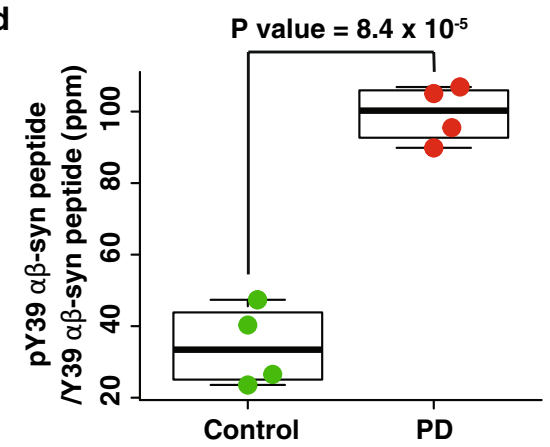

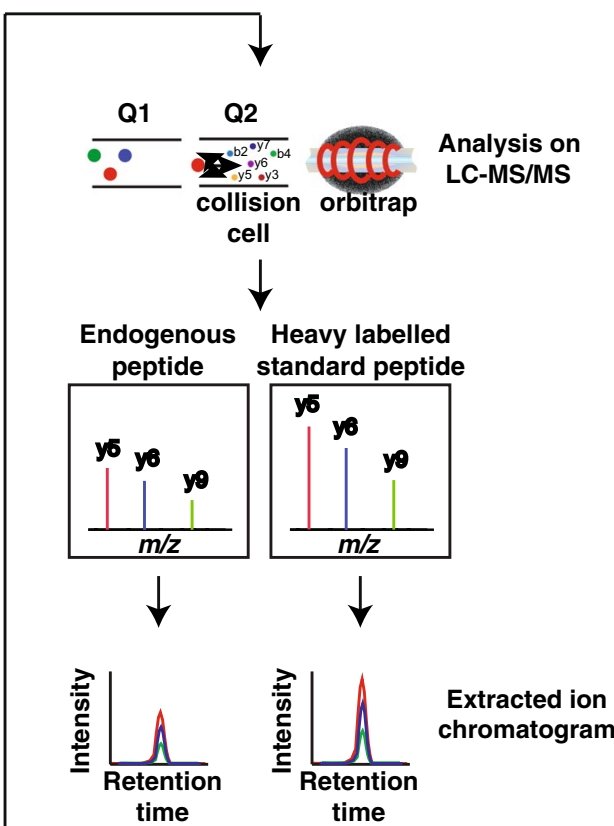

C

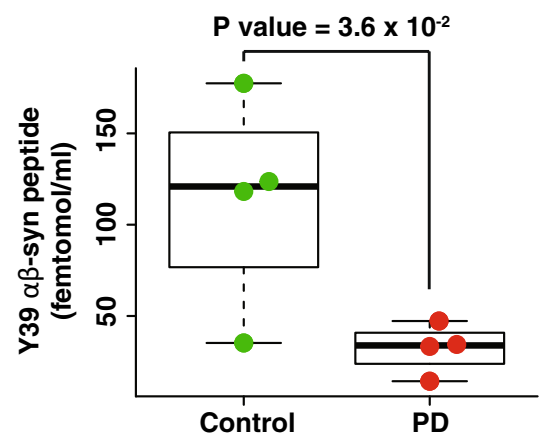

Fig. 4 Quantification of $\mathrm{pY} 39$ aß-syn peptide in CSF samples from PD and control individuals. a The experimental strategy for pY39 aß-syn peptide enrichment from PD and control CSFs using the two-step enrichment approach. CSF proteins were digested with Lys-C and trypsin followed by the two-step enrichment. To minimize experimental biases, heavy standard pY39 aß-syn peptide was added before starting the experiment. The endogenous light and heavy standard PY39 a 3 -syn peptides were monitored under PRM mode followed by quantification using Skyline software. b The abundances of pY39 aß-syn peptide in PD and control CSFs. c The abundances of Y39 a 3 -syn peptide in PD and control CSFs. d The relative abundance of pY39 to Y39 aß-syn peptide in PD and control CSFs 


\section{Supplementary information}

Supplementary information accompanies this paper at https://doi. org/10.1186/s12014-020-09277-8.

Additional file 1: Table S1. The demographic and clinical characteristics of PD patients and control individuals.

Additional file 2: Figure S1. Calibration curve of the heavy synthetic pY39 aß-syn peptide in the presence of $10 \mathrm{ng}$ or $2 \mu \mathrm{g}$ of CSF peptides.

Additional file 3: Table S2. Quantification results for Y39 aß-syn and pY39 aß-syn peptides in the CSF of PD patients and control individuals.

Additional file 4. Skyline files of the quantification results for pY39 aß-syn peptide in the CSF of PD patients and control individuals.

Additional file 5: Figure S2. Experimental strategy for the quantification of the Y39 a-syn peptide in CSF.

\section{Abbreviations}

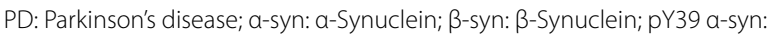
Phosphorylation of the tyrosine residue at position 39 of a-syn; pY39 aß-syn peptide: EGVLpYVGSK sequence; Y39 aß-syn peptide: EGVLYVGSK sequence; $\mathrm{TiO}_{2}$ : Titanium oxide; PTMs: Post-translational modifications; PRM: Parallel reaction monitoring; NPH: Normal pressure hydrocephalus.

\section{Acknowledgements}

The authors acknowledge the joint participation by the Diana Helis Henry Medical Research Foundation through its direct engagement in the continuous active conduct of medical research in conjunction with The Johns Hopkins Hospital and the Johns Hopkins University School of Medicine and the Foundation's Parkinson's Disease Program H-2013. T.M.D. is the Leonard and Madlyn Abramson Professor in Neurodegenerative Diseases. We also acknowledge the support of the shared instrumentation Grant (S10OD021844).

\section{Authors' contributions}

CHN, TMD, and AP designed research; LSR and ARM collected CSF; CHN and GS performed mass spectrometry analysis. CHN, GS, LSR, ARM, VLD, TMD and AP wrote the manuscript. CHN, TMD and AP supervised research. All authors read and approved the final manuscript.

\section{Funding}

This work was supported by NIH Grants NINDS, P50NS38377 and U01NS082133, U01NS097049 and the Wellcome Trust/DBT India Alliance Margdarshi Fellowship (Grant Number IA/M/15/1/502023 to AP).

\section{Availability of data and materials}

All mass spectrometry data and search results have been deposited in the ProteomeXchange Consortium via the PRIDE partner repository with the dataset identifier PXD012202 and project name'Development of a method for the quantification of tyrosine 39 phosphorylated a-syn in human cerebrospinal fluid' [16]. Reviewers can access the dataset by using 'reviewer43678@ebi.ac.uk' as ID and 'jnapGY1k' as a password.

\section{Ethics approval and consent to participate}

This study was approved by the Johns Hopkins University School of Medicine Institutional Review Board. Informed consent was obtained from all study participants.

\section{Consent for publication}

Not applicable.

\section{Competing interests}

We have no conflict of interest to declare.

\section{Author details}

${ }^{1}$ Neurodegeneration Program, Institute for Cell Engineering, Johns Hopkins University School of Medicine, Baltimore, MD 21205, USA. ${ }^{2}$ Department of Neurology, Johns Hopkins University School of Medicine, Baltimore, MD 21205, USA. ${ }^{3}$ Diana Helis Henry Medical Research Foundation, New Orleans,
LA 70130, USA. ${ }^{4}$ Department of Biological Chemistry, McKusick-Nathans Institute of Genetic Medicine, Johns Hopkins University School of Medicine, Baltimore, MD 21205, USA. ${ }^{5}$ Department of Physiology, Johns Hopkins University School of Medicine, Baltimore, MD 21205, USA. ${ }^{6}$ Solomon H. Snyder Department of Neuroscience, Johns Hopkins University School of Medicine, Baltimore, MD 21205, USA. ${ }^{7}$ Department of Pharmacology and Molecular Sciences, Johns Hopkins University School of Medicine, Baltimore, MD 21205, USA. ${ }^{8}$ Manipal Academy of Higher Education (MAHE), Manipal 576104, Karnataka, India. ${ }^{9}$ Present Address: Center for Molecular Medicine, National Institute of Mental Health and Neurosciences (NIMHANS), Hosur Road, Bangalore 560 029, India. ${ }^{10}$ Present Address: Laboratory Medicine and Pathology, Mayo Clinic, Rochester, MN 55902, USA

Received: 1 January 2020 Accepted: 18 April 2020

Published online: 04 May 2020

\section{References}

1. Brahmachari S, et al. c-Abl and Parkinson's disease: mechanisms and therapeutic potential. J Parkinsons Dis. 2017;7(4):589-601.

2. Oueslati A. Implication of alpha-synuclein phosphorylation at S129 in synucleinopathies: what have we learned in the last decade? J Parkinsons Dis. 2016:6(1):39-51.

3. Brahmachari $\mathrm{S}$, et al. Activation of tyrosine kinase c-Abl contributes to alpha-synuclein-induced neurodegeneration. J Clin Invest. 2016;126(8):2970-88.

4. Burmann BM, et al. Regulation of alpha-synuclein by chaperones in mammalian cells. Nature. 2020;577(7788):127-32. https://doi. org/10.1038/s41586-019-1808-9.

5. Jimenez-Jimenez FJ, et al. Cerebrospinal fluid biochemical studies in patients with Parkinson's disease: toward a potential search for biomarkers for this disease. Front Cell Neurosci. 2014:8:369.

6. Bourmaud A, Gallien S, Domon B. Parallel reaction monitoring using quadrupole-Orbitrap mass spectrometer: principle and applications. Proteomics. 2016;16(15-16):2146-59.

7. Brinkmalm G, et al. A parallel reaction monitoring mass spectrometric method for analysis of potential CSF biomarkers for Alzheimer's disease. Proteom Clin Appl. 2018;12:1.

8. Preisinger $\mathrm{C}$, et al. Imatinib-dependent tyrosine phosphorylation profiling of Bcr-Abl-positive chronic myeloid leukemia cells. Leukemia. 2013;27(3):743-6.

9. Ciccimaro E, Hanks SK, Blair IA. Quantification of focal adhesion kinase activation loop phosphorylation as a biomarker of Src activity. Mol Pharmacol. 2009;75(3):658-66.

10. Razavi $M$, et al. High precision quantification of human plasma proteins using the automated SISCAPA Immuno-MS workflow. New Biotechnol. 2016;33(5):494-502.

11. Hughes AJ, et al. Accuracy of clinical diagnosis of idiopathic Parkinson's disease: a clinico-pathological study of 100 cases. J Neurol Neurosurg Psychiatry. 1992;55(3):181-4.

12. Tan H, et al. Refined phosphopeptide enrichment by phosphate additive and the analysis of human brain phosphoproteome. Proteomics. 2015;15(2-3):500-7.

13. Addona TA, et al. Multi-site assessment of the precision and reproducibility of multiple reaction monitoring-based measurements of proteins in plasma. Nat Biotechnol. 2009:27(7):633-41.

14. MacLean B, et al. Skyline: an open source document editor for creating and analyzing targeted proteomics experiments. Bioinformatics. 2010;26(7):966-8.

15. Shuford CM, et al. Peptide production and decay rates affect the quantitative accuracy of protein cleavage isotope dilution mass spectrometry (PC-IDMS). Mol Cell Proteom. 2012;11(9):814-23.

16. Vizcaino JA, et al. 2016 update of the PRIDE database and its related tools. Nucleic Acids Res. 2016;44(D1):D447-56.

\section{Publisher's Note}

Springer Nature remains neutral with regard to jurisdictional claims in published maps and institutional affiliations. 